\title{
Mitochondria, calcium and pro-apoptotic proteins as mediators in cell death signaling
}

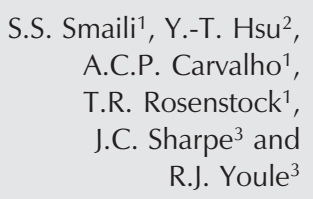

${ }^{1}$ Departamento de Farmacologia, Instituto de Farmacologia, Escola Paulista de Medicina, Universidade Federal de São Paulo, São Paulo, SP, Brasil ${ }^{2}$ Department of Biochemistry, University of Southern Carolina, Charleston, SC, USA ${ }^{3}$ Biochemistry Section, NINDS, National Institutes of Health, Bethesda, MD, USA

\begin{abstract}
Correspondence
S.S. Smaili

Rua Tres de Maio, 100

04044-020 São Paulo, SP

Brasil

Fax: +55-11-5576-4449

E-mail: ssmaili.farm@infar.epm.br

Research supported by FAPESP, CNPq and the National Institutes of Health.
\end{abstract}

Received April 25, 2002

Accepted November 29, 2002

\begin{abstract}
Cellular $\mathrm{Ca}^{2+}$ signals are crucial in the control of most physiological processes, cell injury and programmed cell death through the regulation of a number of $\mathrm{Ca}^{2+}$-dependent enzymes such as phospholipases, proteases, and nucleases. Mitochondria along with the endoplasmic reticulum play pivotal roles in regulating intracellular $\mathrm{Ca}^{2+}$ content. Mitochondria are endowed with multiple $\mathrm{Ca}^{2+}$ transport mechanisms by which they take up and release $\mathrm{Ca}^{2+}$ across their inner membrane. During cellular $\mathrm{Ca}^{2+}$ overload, mitochondria take up cytosolic $\mathrm{Ca}^{2+}$, which in turn induces opening of permeability transition pores and disrupts the mitochondrial membrane potential $\left(\Delta \psi_{\mathrm{m}}\right)$. The collapse of $\Delta \psi_{\mathrm{m}}$ along with the release of cytochrome c from mitochondria is followed by the activation of caspases, nuclear fragmentation and cell death. Members of the Bcl-2 family are a group of proteins that play important roles in apoptosis regulation. Members of this family appear to differentially regulate intracellular $\mathrm{Ca}^{2+}$ level. Translocation of Bax, an apoptotic signaling protein, from the cytosol to the mitochondrial membrane is another step in this apoptosis signaling pathway.
\end{abstract}

Key words

- $\mathrm{Ca}^{2+}$

- Mitochondrial $\mathrm{Ca}^{2+}$ uptake

- Mitochondrial $\mathrm{Ca}^{2+}$ efflux

- Permeability transition

- Apoptosis

- Bcl-2 family

- Bax and apoptosis

\section{Cell death and apoptosis}

Cell death is a primordial event in cell life and there are several mechanisms by which cells achieve death. Necrotic death and apoptotic death are characterized by biochemical and morphological differences. Necrosis is usually involved in some death stimuli and therefore is always pathological, accidental and not very well regulated. Conversely, apoptosis or programmed cell death is a regulated physiological process that is involved in cell maintenance, development, tumor regression, hormone-induced atrophy, and cell- mediated immunity. Apoptosis also occurs during certain pathological states, such as ischemia-reperfusion damage, infarction, neurodegenerative diseases and viral or chemical toxicity, and can be triggered by activation of certain death receptors on the plasma membrane or by cellular stress. The main interest in apoptotic mechanisms is the fact that apoptosis involves a cascade of biochemical events that is tightly regulated. Some of the elements in this cascade are the activation of specific cysteine proteases, called caspases, mitochondrial release of death factors, and finally the characteristic changes in 
nuclear morphology and DNA fragmentation (1). Several lines of evidence suggest that a change in cellular $\mathrm{Ca}^{2+}$ handling and an increase in cytosolic $\mathrm{Ca}^{2+},\left[\mathrm{Ca}^{2+}\right]_{\mathrm{c}}$, might be associated with apoptotic signaling (2).

The mitochondrial membrane potential $\left(\Delta \psi_{\mathrm{m}}\right)$ has been identified as an important hallmark associated with apoptotic cell death. During apoptosis nuclear disintegration can be preceded by loss of $\Delta \psi_{\mathrm{m}}$ (3), and disruption of $\Delta \psi_{\mathrm{m}}$ associated with several factors such as an increase in reactive oxygen species production and elevation of $\left[\mathrm{Ca}^{2+}\right]_{\mathrm{c}}(4)$. Under certain circumstances, loss of $\Delta \psi_{\mathrm{m}}$ during apoptosis is prevented by cyclosporine $\mathrm{A}$, indicating that permeability transition may be involved in apoptosis (5). During apoptotic signaling, cytochrome c, apoptosis-inducing factor, caspases and other mitochondrial factors like smac/DIABLO, are released from mitochondria (6). Both apoptosis-inducing factor and cytochrome $\mathrm{c}$, when released from mitochondria into the cytosol, induce activation of pro-caspases and caspases. Release of cytochrome c can be related to the full opening of the permeability transition pore (PTP) (7). However, as discussed below, the precise nature of the release of cytochrome $\mathrm{c}$ and other factors from mitochondria certainly requires further examination.

\section{Mitochondria and cell death}

A number of investigators have shown that during cell death mitochondria lose their $\Delta \psi_{\mathrm{m}}$. This loss of $\Delta \psi_{\mathrm{m}}$ was inhibited by cyclosporine A, a PTP inhibitor, suggesting that PTP may be involved in this process $(4,5)$.

The PTP has been reported to be a megachannel on the mitochondrial membrane and the opening of this pore may cause the release of solutes up to $1.5 \mathrm{kDa}$, inducing the collapse of the proton gradient and thus impairing ATP synthesis and leading to mitochondrial dysfunction (8). Although the existence of such a mechanism has been established for over 20 years (9), the exact nature of the pore and its molecular structure are still unknown. It has been proposed that the PTP is composed of a mitochondrial cyclophylin D located in the matrix and is bound to the inner mitochondrial membrane (10). The binding of cyclophylin D to the adenine nucleotide translocase on the inner membrane causes a conformational change in adenine nucleotide translocase (11). In addition, other mitochondrial constituents, such as creatinine kinase, located in the inter-membrane space, mitochondrial porin known as voltage-dependent anion channel, present on the outer membrane, may all form part of the PTP complex (12).

It is known that the opening of the PTP in the high conductance mode is triggered by increases in $\mathrm{Ca}^{2+}$ concentration and changes in mitochondrial voltage, $\mathrm{pH}$ and redox state (13). Reactive oxygen species are also related to the opening of the pore (14). Because of the dramatic change in membrane permeability that occurs upon opening of the PTP and collapse of the $\Delta \psi_{\mathrm{m}}$, ATP synthesis is uncoupled from oxidative phosphorylation and mitochondrial swelling occurs, leading to cellular pathology.

It has been shown and discussed more recently that opening of the PTP occurs in a low conductance state which can be related to the transient openings of the pore $(15,16)$. Although this mechanism is still not well understood, it might be related to $\mathrm{Ca}^{2+}$ signaling $(15,16)$, oxygen utilization, and to the reduction in $\Delta \psi_{\mathrm{m}}$ reducing the formation of superoxide due to leakage of electrons from the mitochondrial electron transport chain (17). Further investigation of this subject is required.

\section{Proteins of the Bcl-2 family and apoptosis. Mitochondrial modulation}

Members of the Bcl-2 family form a group of proteins that play important roles in the 
regulation of cell death under both physiological and pathological conditions. Members of this family promote either cell survival, as in the case of Bcl-2 and Bcl- $\mathrm{X}_{\mathrm{L}}$, or cell death, as in the case of Bax and Bid $(2,18)$. In living cells, Bax and Bid are predominantly soluble proteins (19), Bcl-2 is associated with the membranes of various organelles including endoplasmic reticulum, mitochondria, and nuclei (20), and Bcl- $\mathrm{X}_{\mathrm{L}}$ exists in both soluble and membrane-bound forms (19). During apoptosis, Bcl-2 remains bound to the membranes, but the cytosolic forms of Bax, Bid and Bcl- $\mathrm{X}_{\mathrm{L}}$ have been found to redistribute from the cytosol into the membranes, in particular mitochondrial membranes $(19,21)$. The mechanisms leading to $\mathrm{Bax}$ and $\mathrm{Bcl}-\mathrm{X}_{\mathrm{L}}$ redistribution into the mitochondria are still unknown. Bid is believed to be post-translationally cleaved by caspase- 8 to enable its translocation into mitochondria (21).

X-ray crystallography and solution NMR analyses of the recombinant $\mathrm{Bcl}-\mathrm{X}_{\mathrm{L}}$ have indicated that this protein shares a high degree of structural similarity to the translocation domain of diphtheria toxin (22), which can insert into lipid bilayers (23). This suggests that $\mathrm{Bcl}-2, \mathrm{Bcl}-\mathrm{X}_{\mathrm{L}}$, and Bax may form ion channels (24). In vitro studies have shown that the insertion of Bax causes the release of cytochrome $\mathrm{c}$ from mitochondria (25). Cytochrome $\mathrm{c}$ has been proposed to interact with Apaf-1 (26). This complex, in the presence of dATP, can catalyze the activation of caspases to proteolyze cellular constituents (27). Figure 1 shows a schematic representation of the apoptotic cascade and the interaction of Bax and Bid with mitochondria.

Some reports have suggested that this release of cytochrome $\mathrm{c}$ is associated with Bax interaction with adenine nucleotide translocase (7) or voltage-dependent anion channels (28), both of which are putative components of the PTP. Thus, release of cytochrome c can be associated with PTP activation and the attending loss of $\Delta \psi_{\mathrm{m}}$.

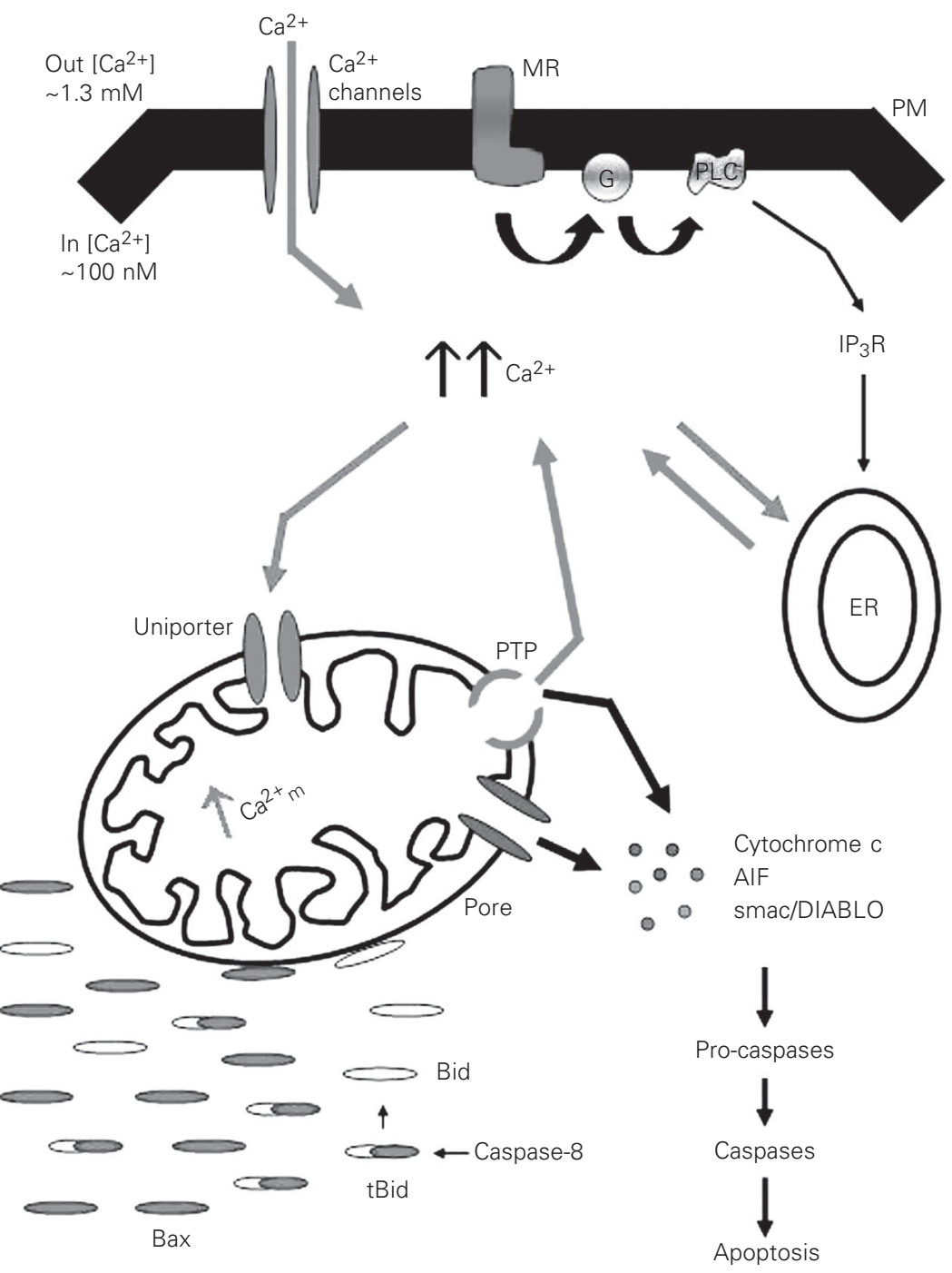

Figure 1. $\mathrm{Ca}^{2+}$ homeostasis and signaling under physiological and cell death conditions. Without stimuli, extracellular $\mathrm{Ca}^{2+}$ concentration is approximately $1.3 \mathrm{mM}$ and cytosolic concentration is about $100 \mathrm{nM}$. When metabotropic receptors (MR) are stimulated cytosolic $\mathrm{Ca}^{2+}$ increases either by opening of membrane $\mathrm{Ca}^{2+}$ channels or release from intracellular stores. Transient increases in cytosolic $\mathrm{Ca}^{2+}$ stimulate mitochondrial uptake of $\mathrm{Ca}^{2+}$ which is found in close proximity to the sarcoendoplasmic reticulum. Mitochondrial $\mathrm{Ca}^{2+}$ $\left(\mathrm{Ca}^{2+} \mathrm{m}\right)$ accumulation leads to opening of the permeability transition pore (PTP; either at a high or low conductance). In the presence of an apoptotic signal cells may overexpress proapoptotic proteins such as Bax and Bid. Bax can translocate from the cytosol to the membranes, especially mitochondria. When Bid is cleaved (truncated Bid, tBid) by caspases, Bid translocates into the mitochondria increasing Bax toxicity. Bax and Bid lead to a permeabilization of mitochondrial membranes via mechanisms that are still under investigation (e.g., pore formation, opening of PTP). This permeabilization leads to the release of cytochrome $\mathrm{c}$ and other factors such as apoptosis-inducing factor (AIF), second mitochondrial activator of caspases (smac/DIABLO) that activate pro-caspases and down caspases that execute the proteolytic cascade, DNA fragmentation and cell death. During apoptotic stimuli, $\mathrm{Ca}^{2+}$ may be released from the endoplasmic reticulum (ER) and be taken up by mitochondria. The $\mathrm{Ca}^{2+}$ content of the intracellular stores can accelerate apoptosis, but the exact relationship between $\mathrm{Ca}^{2+}$ signaling and apoptosis is still unknown. PM, plasma membrane; $I P_{3} R$, inositoltriphosphate receptor; $G$, G protein; PLC, phospholipase C. 
However, cytochrome c release can occur in the absence of permeability transition and collapse of $\Delta \psi_{\mathrm{m}}$ (29). In addition, under special circumstances permeability transition has been shown not to be involved in Bax-induced cytochrome c release (30). Since the nature of PTP and its molecular identity are unknown, the mechanism of PTP activation and its participation in cytochrome $\mathrm{c}$ release and loss of $\Delta \psi_{\mathrm{m}}$ are not clearly understood and need further investigation.

\section{Bax as apoptotic protein}

Bax is a pro-apoptotic member of the Bcl-2 family. Members of this family can promote either cell survival, as is the case for $\mathrm{Bcl}-2$ and $\mathrm{Bcl}-\mathrm{X}_{\mathrm{L}}$, or cell death, as is the case
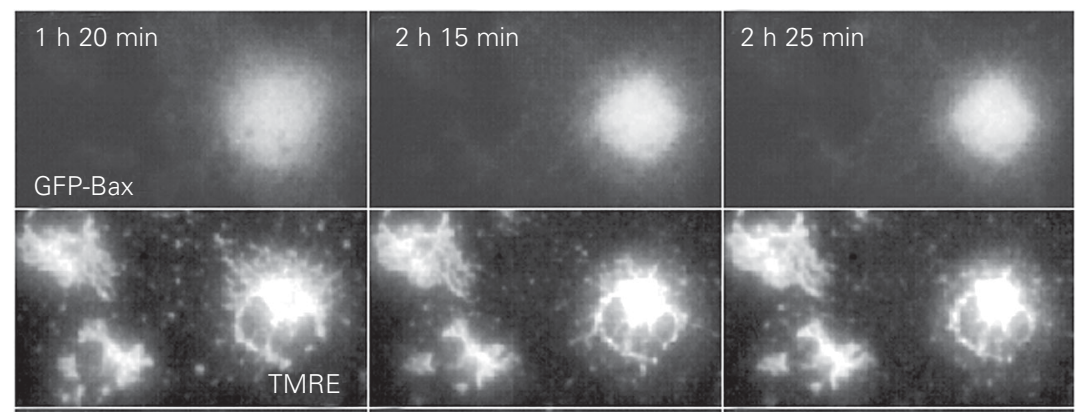

$2 \mathrm{~h} 35 \mathrm{~min}$
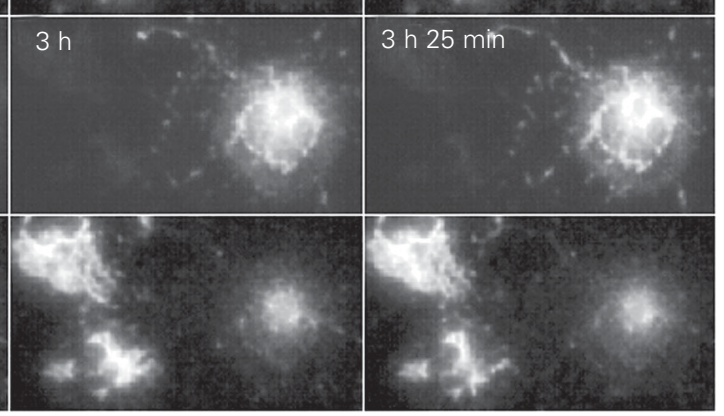

Figure 2. Loss of mitochondrial membrane potential $\left(\Delta \psi_{\mathrm{m}}\right)$ is associated with Bax translocation to mitochondria. Healthy Cos-7 cells expressing GFP-Bax (rows 1 and 3) were costained with tetramethylrhodamine ethyl ester (TMRE, $50 \mathrm{nM}$ ) for $\Delta \psi_{\mathrm{m}}$ visualization (rows 2 and 4). Cells were then treated with the apoptotic inducer staurosporine (STS, $1 \mu \mathrm{M})$ and fluorescences of GFP-Bax and TMRE were simultaneously recorded. The cells on the right were transfected with GFP-Bax (rows 1 and 3) while two others on the left were not transfected with GFP-Bax but were stained with TMRE (rows 2 and 4). In the first panel at a specific time (1 $\mathrm{h}$ and $20 \mathrm{~min}$ ) after STS treatment, Bax (row 1) was still soluble in the cytosol and the $\Delta \psi_{m}$ (row 2) was well maintained. Over time, GFP-Bax shifted from a diffuse cytosolic state to a punctuated mitochondrial-bound localization (row 3). The presence of GFP-Bax in the mitochondria promoted the collapse of $\Delta \psi_{m}$ as indicated by the decrease in TMRE fluorescence (row 4). This loss may occur concomitantly with GFP-Bax translocation to mitochondrial membranes. In the two untransfected cells the collapse of $\Delta \psi_{\mathrm{m}}$ was not observed. for Bax and Bak. Bax was first identified as a Bcl-2 binding partner by immunoprecipitation (31). Subsequently it was shown that overexpression of Bax can accelerate cell death in response to various apoptosis stimuli (32). Physiologically, Bax plays an important role in neuronal development and spermatogenesis. Animals that are deficient in Bax have increased numbers of neurons and males are known to be sterile (33). Under pathological conditions such as cerebral and cardiac ischemia, upregulation of Bax has been reported in the afflicted area of the tissues, implicating the participation of this protein in the promotion of neuronal and cardiomyocytic cell death (34). In certain cases of human colorectal cancer, mutations were found in the gene encoding Bax, suggesting that inactivation of Bax promotes tumorigenesis by rendering the tumor cells less susceptible to cell death (35).

Bax shares with other members of the Bcl-2 family the feature of having three conserved regions named $\mathrm{BH}$ (Bcl-2 homology) domains 1-3 (36). Several lines of evidence show that these domains can be important for the regulatory functions of these $\mathrm{Bcl}-2$ family proteins. In addition, Bax and a number of Bcl-2 family members also possess a hydrophobic segment at their $\mathrm{C}$-terminal ends. For Bcl-2, this hydrophobic segment is required to anchor the protein to various organelles, including endoplasmic reticulum, mitochondria, and nuclear outer membranes (36). The 3-D structures of the Bax and its pro-survival antagonist $\mathrm{Bcl}-\mathrm{X}_{\mathrm{L}}$ have recently been deciphered (37). These two proteins appear to share a significant structural homology with the translocation domain of diphtheria toxin, especially in a helical loop domain formed by $\alpha$-helices 5 and 6 . This particular domain of diphtheria toxin has been shown to penetrate the lipid bilayer to form pores $(22,23)$.

In healthy cells, Bax is predominantly a soluble monomeric protein (19) despite the fact that it possesses a C-terminal hydropho- 
bic segment. This hydrophobic domain, unlike those of $\mathrm{Bcl}-2$ and $\mathrm{Bcl}-\mathrm{X}_{\mathrm{L}}$, is sequestered inside a hydrophobic cleft (37). Upon induction of apoptosis by a variety of agents, a significant fraction of Bax has been observed to translocate from the cytosol to the membrane fractions, in particular, the mitochondria $(19,38)$. This translocation process appears to involve a conformational change in Bax leading to the exposure of its $\mathrm{C}$ terminal hydrophobic domain (39). After translocation, Bax may form large oligomers once they reach the membrane. These oligomers are associated with cytotoxic activities and have not been seen in other proteins such as Bid and Bad (40). Deletion of the Bax C-terminal hydrophobic domain abrogated the ability of the mutant protein to translocate to mitochondria and greatly attenuated its ability to promote cell death. On the other hand, point mutations of Bax that target the expressed proteins to mitochondria greatly increased Bax toxicity $(39,40)$. The translocation of Bax to mitochondria is associated with the release of cytochrome c and the loss of $\Delta \psi_{\mathrm{m}}(25,29)$. These phenomena may be related to the recent observations that Bax can form ion channels or pores in mitochondrial membranes (41). Cytochrome $\mathrm{c}$ activates caspase- 3 leading to the proteolysis of the cell while the loss of $\Delta \psi_{\mathrm{m}}$ corresponds to a decrease in cellular energy production. The pro-apoptotic activity of Bax, however, can be counteracted by co-expression with pro-survival factors $\mathrm{Bcl}-2$ and $\mathrm{Bcl}-$ $\mathrm{X}_{\mathrm{L}}$, which can block Bax translocation to mitochondria during apoptosis (42). In Figure 2 we show Cos- 7 cells tranfected with a GFP-Bax construct. Using this approach, it is possible to visualize that $\mathrm{Bax}$ is soluble in the cytosol of healthy cells and translocates to membranes upon apoptotic stimuli like staurosporine. In our study, we observed that the collapse of $\Delta \psi_{\mathrm{m}}$ occurred just before the complete translocation of Bax to mitochondrial membranes (38). In cells co-expressing Bax and Bcl- $\mathrm{X}_{\mathrm{L}}$, staurosporine was not able to induce either $\Delta \psi_{\mathrm{m}}$ collapse or Bax translocation.

\section{$\mathrm{BH} 3$ domain proteins and cell death}

Bcl-2 family members are classified as having one or more Bcl-2 homology domains (BH domain 1-4). Some members of this family that possess the $\mathrm{BH} 3$ domain alone were named "BH3 domain only". The $\mathrm{BH} 3$ domain proteins such as Bid, Bad, and Bik are critical for heterodimerization with other family members. This interaction may be critical for death-regulatory activity. Caspase cleavage of truncated Bid (tBid) exposes the $\mathrm{BH} 3$ domain, causing its translocation to mitochondria and promoting cytochrome c release (43). In neuronal cells, it has been shown that the $\mathrm{BH} 3$ domain causes a permeabilization of the outer membrane leading to cytochrome $\mathrm{c}$ release without affecting inner membrane integrity or permeability transition. These effects may be dependent on the presence of Bax (44). The caspase-activated tBid is believed to trigger the homo-oligomerization of the pro-apoptotic family members such as Bak and Bax (45). This oligomerization can induce the release of cytochrome c (46). The precise mechanisms by which cytochrome $\mathrm{c}$ is released is not understood; however, to a certain extent, release can be rescued by exogenous cytochrome $\mathrm{c}$, showing a reversible component of mitochondrial respiratory dysfunction during apoptosis (47).

\section{$\mathrm{Ca}^{2+}$ as a sensor in cell death}

Intracellular $\mathrm{Ca}^{2+}$ changes have been implicated in cell death and have been associated with a number of pathological states such as cardiac ischemia, muscular dystrophy, neuronal damage during cerebral ischemia, and hypoglycemia (48). In the central nervous system $\mathrm{Ca}^{2+}$ overload can give rise to excitotoxicity, leading to cellular damage and eventually cell death. Excitotoxic activation of glutamate 
receptors causes a large influx of $\mathrm{Ca}^{2+}$ into the cell, resulting in mitochondrial $\mathrm{Ca}^{2+}$ overload and oxidative damage. It has been postulated that the PTP is associated with the accumulation of $\mathrm{Ca}^{2+}$ (49); however, others have suggested that the opening of the pore may be a consequence of reactive oxygen species production (50).

Mitochondria regulate $\mathrm{Ca}^{2+}$ levels by utilizing the energy derived from the chemiosmotic potential gradient $\left(\Delta \psi_{\mathrm{m}}\right)$ to transport $\mathrm{Ca}^{2+}$ into and out of their matrix. Mitochondria take up $\mathrm{Ca}^{2+}$ through uniporters in mitochondrial inner membranes, utilizing energy derived from $\Delta \psi_{\mathrm{m}}$ (51). This process, however, can be inhibited by polycations such as ruthenium red. This uptake mechanism serves to support $\mathrm{Ca}^{2+}$-sensitive mitochondrial enzymes and acts as a mechanism for removal of $\left[\mathrm{Ca}^{2+}\right]_{\mathrm{c}}$ from local areas of the cell.

$\mathrm{Ca}^{2+}$ efflux from mitochondria into the cytosol occurs via at least two different mechanisms, an $\mathrm{Na}^{+}$-dependent transport process and an $\mathrm{Na}^{+}$-independent one that exchange $\mathrm{Ca}^{2+}$ for $\mathrm{Na}^{+}$or $\mathrm{H}^{+}$, respectively. The $\mathrm{Na}^{+}$-dependent mechanism, also known as mitochondrial $\mathrm{Na}^{+} / \mathrm{Ca}^{2+}$ exchanger, is mainly found in heart and brain mitochondria and is an electrogenic process (52). In contrast, the $\mathrm{Na}^{+}$-independent efflux, is nonelectrogenic, and is present in liver and kidney mitochondria, and behaves as an active $\mathrm{Ca}^{2+} / 2 \mathrm{H}^{+}$exchanger (51).

Cytosolic $\mathrm{Ca}^{2+}$ has been proposed to play an important role in the triggering of apoptotic signals in the regulation of cell deathspecific enzymes such as endonucleases (53). Recent studies have shown that $\mathrm{Ca}^{2+}$ stores in the endoplasmic reticulum may play a role in apoptotic induction, since a reduction of $\mathrm{Ca}^{2+}$ release from the endoplasmic reticulum can prevent mitochondrial damage. Endoplasmic reticulum $\mathrm{Ca}^{2+}$ release can also sensitize mitochondria to release cytochrome c, and pro-apoptotic proteins such as Bax and Bak have been suggested to play a role in this process (54). Calcium signals have been iden- tified as one of the major signals which converge on mitochondria to trigger the mitochondrial-dependent pathway of cardiac apoptotic cell death (55). Currently, it is not clear what roles Bcl-2 family members play in $\mathrm{Ca}^{2+}$ signaling during cell death. Some investigators have shown that they play a modulatory role, since overexpression of these proteins can change $\mathrm{Ca}^{2+}$ concentration in the cytosol or in the intracellular stores. Overexpression of $\mathrm{Bcl}-2$ has been reported to prevent $\mathrm{Ca}^{2+}$ release from the endoplasmic reticulum in response to apoptotic inducers such as thapsigargin (56). Recently, it has been shown that overexpression of Bax in cultured cells caused a loss of endoplasmic reticulum content, and depletion of endoplasmic reticulum by rynodine receptors enhances Bax interaction with mitochondria (57). Also, caffeine and other xanthines that mobilize intracellular $\mathrm{Ca}^{2+}$ can act synergistically with $\mathrm{p} 53$ to induce cell death involving Bax translocation (58).

The role of different members of the Bcl2 family and their relation with calcium signals is still unknown. Recent reports have associated tBid with $\mathrm{Ca}^{2+}$ signaling and propagation to mitochondria. It is possible that $\mathrm{tBid}$ induces a selective permeabilization of the outer mitochondrial membrane to inositoltriphosphate-induced mitochondrial $\mathrm{Ca}^{2+}$ signaling (59). This change in mitochondrial permeability might be related to the tBid-induced remodeling of mitochondrial structure that evokes a mobilization of the cytochrome c stores (60). The consequences of the effect of tBid and its interactions with Bax translocation and $\mathrm{Ca}^{2+}$ homeostasis still await elucidation.

Currently, little is known about the mechanism of apoptosis. The role of the Bcl-2 family, the PTP and $\mathrm{Ca}^{2+}$ signaling, and how these pathways interact to regulate this process are still unknown. Further work is needed to elucidate these mechanisms in order to understand their role in tissue homeostasis and disease progression. 


\section{References}

1. Green DR \& Reed JC (1998). Mitochondria and apoptosis. Science, 281: 1309-1311.

2. Smaili SS, Hsu YT, Youle RJ \& Russell JT (2000). Mitochondria in $\mathrm{Ca}^{2+}$ signaling and apoptosis. Journal of Bioenergetics and Biomembranes, 32: 35-46.

3. Marchetti P, Hirsch T, Zamzami N, Castedo M, Decaudin D, Susin SA, Masse B \& Kroemer G (1996). Mitochondrial permeability transition triggers lymphocyte apoptosis. Journal of Immunology, 157: 4830-4836.

4. Macho A, Hirsch T, Marzo I, Marchetti P, Dallaporta B, Susin SA, Zamzami N \& Kroemer G (1997). Glutathione depletion is an early and calcium elevation is a late event of thymocyte apoptosis. Journal of Immunology, 158: 4612-4619.

5. Kroemer G, Dallaporta B \& Resche-Rigon M (1998). The mitochondrial death/life regulator in apoptosis and necrosis. Annual Review of Physiology, 60: 619-642.

6. Du C, Fang M, Li Y, Li L \& Wang X (2000). Smac, a mitochondrial protein that promotes cytochrome c-dependent caspase activation by eliminating IAP inhibition. Cell, 102: 33-42.

7. Marzo I, Brenner C, Zamzami N, Jurgensmeier JM, Susin SA, Vieira HL, Prevost MC, Xie Z, Matsuyama S, Reed JC \& Kroemer G (1998). Bax and adenine nucleotide translocator cooperate in the mitochondrial control of apoptosis. Science, 281: 2027-2031.

8. Hoek JB, Farber JL, Thomas AP \& Wang X (1995). Calcium iondependent signalling and mitochondrial dysfunction: mitochondrial calcium uptake during hormonal stimulation in intact liver cells and its implication for the mitochondrial permeability transition. Biochimica et Biophysica Acta, 1271: 93-102.

9. Lehninger AL, Vercesi A \& Bababunmi EA (1978). Regulation of $\mathrm{Ca}^{2+}$ release from mitochondria by the oxidation-reduction state of pyridine nucleotides. Proceedings of the National Academy of Sciences, USA, 75: 1690-1694.

10. Connern CP \& Halestrap AP (1992). Purification and N-terminal sequencing of peptidyl-prolyl cis-trans-isomerase from rat liver mitochondrial matrix reveals the existence of a distinct mitochondrial cyclophylin. Biochemical Journal, 284: 381-385.

11. Halestrap AP, Woodfield KY \& Connern CP (1997). Oxidative stress, thiol reagents, and membrane potential modulate the mitochondrial permeability transition by affecting nucleotide binding to the adenine nucleotide translocase. Journal of Biological Chemistry, 272: 3346-3354.

12. Beutner G, Rück A, Riede B \& Brdiczka D (1998). Complexes between porin, hexokinase, mitochondrial creatine kinase and adenylate translocator display properties of the permeability transition pore. Implication for regulation of permeability transition by the kinases. Biochimica et Biophysica Acta, 1368: 7-18.

13. Kowaltowski AJ, Castilho RF \& Vercesi AE (2001). Mitochondrial permeability transition and oxidative stress. FEBS Letters, 495: 1215.

14. Vercesi AE, Kowaltowski AJ, Grijalba MT, Meinicke AR \& Castilho RF (1997). The role of reactive oxygen species in mitochondrial permeability transition. Bioscience Reports, 17: 43-52.

15. Smaili SS \& Russell JT (1999). Permeability transition pore regulates both mitochondrial membrane potential and agonist-evoked $\mathrm{Ca}^{2+}$ signals in oligodendrocyte progenitors. Cell Calcium, 26: 121-130.

16. Smaili SS, Stelatto KA, Burnet $P$, Thomas AP \& Gaspers LD (2001). Cyclosporin A inhibits inositol 1,4,5-trisphosphate-dependent $\mathrm{Ca}^{2+}$ signals by enhancing $\mathrm{Ca}^{2+}$ uptake into the endoplasmic reticulum and mitochondria. Journal of Biological Chemistry, 276: 2332923340.

17. Skulachev VP (1997). Membrane-linked systems preventing superoxide formation. Bioscience Reports, 17: 347-366.

18. Adams JM \& Cory S (1998). The Bcl-2 protein family: arbiters of cell survival. Science, 281: 1322-1326.

19. Hsu YT, Wolter KG \& Youle RJ (1997). Cytosol-to-membrane redistribution of $\mathrm{Bax}$ and $\mathrm{Bcl}-\mathrm{X}_{\mathrm{L}}$ during apoptosis. Proceedings of the National Academy of Sciences, USA, 94: 3668-3672.

20. Krajewski S, Krajewski M, Shabaik A, Miyashita T, Wang HG \& Reed JC (1994). Immunohistochemical determination of in vivo distribution of Bax, a dominant inhibitor of Bcl-2. American Journal of Pathology, 145: 1326-1336.

21. Li H, Zhu H, Xu CJ \& Yuan J (1998). Cleavage of BID by caspase 8 mediates the mitochondrial damage in the Fas pathway of apoptosis. Cell, 94: 491-501.

22. Muchmore SW, Sattler M, Liang $H$ et al. (1996). X-ray and NMR structure of human $\mathrm{Bcl}-\mathrm{xL}$, an inhibitor of programmed cell death. Nature, 381: 335-341.

23. Kagan BL, Finkelstein A \& Colombini M (1981). Diphtheria toxin fragment forms large pores in phospholipid bilayer membranes. Proceedings of the National Academy of Sciences, USA, 78: 49504954.

24. Schlesinger $\mathrm{PH}$, Gross $A$, Yin XM, Yamamoto $K$, Saito $M$, Waksman G \& Korsmeyer SJ (1997). Comparison of the ion channel characteristics of proapoptotic BAX and antiapoptotic BCL-2. Proceedings of the National Academy of Sciences, USA, 94: 11357-11362.

25. Jurgensmeier JM, Xie Z, Deveraux Q, Ellerby L, Bredesen D \& Reed JC (1998). Bax directly induces release of cytochrome c from isolated mitochondria. Proceedings of the National Academy of Sciences, USA, 95: 4997-5002.

26. Zou H, Henzel WJ, Liu X, Lutschg A \& Wang X (1997). Apaf-1, a human protein homologous to $C$. elegans CED-4, participates in cytochrome c-dependent activation of caspase-3. Cell, 90: 405-413.

27. Li P, Nijhawan D, Budihardjo I, Srinivasula SM, Ahmad M, Alnemri ES \& Wang X (1997). Cytochrome $c$ and dATP-dependent formation of Apaf-1/caspase-9 complex initiates an apoptotic protease cascade. Cell, 91: 479-489.

28. Narita M, Shimizu S, Ito $T$, Chittenden $T$, Lutz RJ, Matsuda $H$ \& Tsujimoto $Y$ (1998). Bax interacts with the permeability transition pore to induce permeability transition and cytochrome $c$ release in isolated mitochondria. Proceedings of the National Academy of Sciences, USA, 95: 14681-14686.

29. Goldstein JC, Waterhouse NJ, Juin P, Evan GI \& Green DR (2000). The coordinate release of cytochrome $\mathrm{C}$ during apoptosis is rapid, complete and kinetically invariant. Nature Cell Biology, 2: 156-162.

30. Eskes R, Antonsson B, Osen-Sand A, Montessuit S, Richter C, Sadoul R, Mazzei E, Nichols A \& Montinou JC (1998). Bax-induced cytochrome $\mathrm{C}$ release from mitochondria is independent of the permeability transition pore but highly dependent on $\mathrm{Mg}^{2+}$ ions. Journal of Cell Biology, 193: 217-224.

31. Oltvai ZN, Milliman CL \& Korsmeyer SJ (1993). Bcl-2 heterodimerizes in vivo with a conserved homolog, Bax, that accelerates programmed cell death. Cell, 74: 609-619.

32. Yang E \& Korsmeyer SJ (1996). Molecular apoptosis: a discourse on the Bcl-2 family and cell death. Blood, 88: 386-401.

33. Knudson CM, Tung KSK, Tourtellote WG, Brown GAJ \& Korsmeyer SJ (1995). Bax-deficient mice with lymphoid hyperplasia and male 
germ cell death. Science, 270: 96-99.

34. Krajewski S, Krajewski M, Kikorska M, Lach B, Chatten J \& Reed JC (1997). Immunohistochemical analysis of Bcl-2, Bcl-X, Mcl-1, and Bax in tumors of central and peripheral nervous system origin. American Journal of Pathology, 150: 805-814.

35. LeBlanc H, Lawrence D, Varfolomeev E, Totpal K, Morlan J, Schow P, Fong S, Schwall R, Sinicropi D \& Ashkenazi A (2002). Tumor-cell resistance to death receptor-induced apoptosis through mutational inactivation of the proapoptotic Bcl-2 homolog Bax. Nature Medicine, 8: 274-281.

36. Zha H, Kisk HA, Yaffe MP, Mahajan N, Herman B \& Reed JC (1996). Structure-function comparisons of the proapoptotic protein Bax in yeast and mammalian cells. Molecular and Cellular Biology, 16: 6494-6508.

37. Suzuki M, Youle RJ \& Tjandra N (2000). Structure of Bax: coregulation of dimer formation and intracellular localization. Cell, 103: 645-654.

38. Smaili SS, Hsu YT, Sanders K, Russell JT \& Youle RJ (2001). Bax translocation to mitochondria subsequent to a rapid loss of mitochondrial membrane potential. Cell Death and Differentiation, 8: 909-920.

39. Nechushtan A, Smith CL, Hsu YT \& Youle RJ (1999). Conformation of the Bax C-terminus regulates subcellular location and cell death. EMBO Journal, 18: 2330-2341.

40. Nechushtan A, Smith CL, Lamensdorf I, Yoon SH \& Youle RJ (2001). Bax and Bak coalesce into novel mitochondria-associated clusters during apoptosis. Journal of Cell Biology, 153: 1265-1276.

41. Antonsson BS, Montessuit S, Lauper S, Eskes R \& Martinou JC (2000). Bax oligomerization is required for channel-forming activity in liposomes and to trigger cytochrome c release from mitochondria. Biochemical Journal, 345 (Part 2): 271-278.

42. Vander Heiden MG, Chandel NS, Williamson EK, Schumacker PT \& Thompson CB (1997). Bcl-xL regulates the membrane potential and volume homeostasis of mitochondria. Cell, 91: 627-637.

43. Gross A, Yin XM, Wang K, Wei MC, Jockel J, Milliman C, ErdjumentBromage H, Tempst P \& Korsmeyer SJ (1999). Caspase cleaved BID targets mitochondria and is required for cytochrome c release, while $\mathrm{BCL}-\mathrm{XL}$ prevents this release but not tumor necrosis factor-R1/Fas death. Journal of Biological Chemistry, 274: 1156-1163.

44. Polster BM, Kinnally KW \& Fiskum G (2001). BH3 death domain peptide induces cell type-selective mitochondrial outer membrane permeability. Journal of Biological Chemistry, 276: 37887-37894.

45. Korsmeyer SJ, Wei MC, Saito M, Weiler S, Oh KJ \& Schlesinger PH (2000). Pro-apoptotic cascade activates BID, which oligomerizes BAK or BAX into pores that result in the release of cytochrome $\mathrm{C}$. Cell Death and Differentiation, 7: 1166-1173.

46. Wei MC, Zong WX, Cheng EH, Lindsten T, Panoutsakopoulou $V$, Ross AJ, Roth KA, MacGregor GR, Thompson CB \& Korsmeyer SJ (2001). Proapoptotic BAX and BAK: a requisite gateway to mitochondrial dysfunction and death. Science, 292: 727-730.

47. Mootha VK, Wei MC, Buttle KF, Scorrano L, Panoutsakopoulou V,
Mannella CA \& Korsmeyer SJ (2001). A reversible component of mitochondrial respiratory dysfunction in apoptosis can be rescued by exogenous cytochrome c. EMBO Journal, 20: 661-671.

48. Budd SL (1998). Mechanisms of neuronal damage in brain hypoxia/ ischemia: focus on the role of mitochondrial calcium accumulation. Pharmacology and Therapeutics, 80: 203-229.

49. Dubinsky JM \& Levi $Y$ (1998). Calcium-induced activation of the mitochondrial permeability transition in hippocampal neurons. Journal of Neuroscience Research, 53: 728-741.

50. Castilho RF, Hansson O, Ward MW, Budd SL \& Nichols DG (1998). Mitochondrial control of acute glutamate excitotoxicity in cultured cerebellar granule cells. Journal of Neuroscience, 18: 10277-10286.

51. Gunter TE, Buntinas L, Sparagna GC \& Gunter KK (1998). The Ca ${ }^{2+}$ transport mechanisms of mitochondria and $\mathrm{Ca}^{2+}$ uptake from physiological-type $\mathrm{Ca}^{2+}$ transients. Biochimica et Biophysica Acta, 1366: 5-15.

52. Baysal K, Jung KK, Gunter KK, Gunter TE \& Brierley GP (1994). Na+dependent $\mathrm{Ca}^{2+}$ efflux mechanism of heart mitochondria is not a passive $\mathrm{Ca}^{2+} / 2 \mathrm{Na}^{+}$exchanger. American Journal of Physiology, 266: C800-C805

53. McConkey DJ \& Orrenius S (1997). The role of calcium in the regulation of apoptosis. Biochemical and Biophysical Research Communications, 239: 357-366.

54. Nutt LK, Pataer A, Pahler J, Fang B, Roth J, McConkey DJ \& Swisher SG (2002). Bax and bak promote apoptosis by modulating endoplasmic reticular and mitochondrial $\mathrm{Ca}^{2+}$ stores. Journal of Biological Chemistry, 277: 9219-9225.

55. Pacher P, Csordas G \& Hajnoczky G (2001). Mitochondrial $\mathrm{Ca}^{2+}$ signaling and cardiac apoptosis. Biological Signals and Receptors, 10: $200-223$.

56. Baffy G, Miyashita T, Williamson JR \& Reed JC (1993). Apoptosis induced by withdrawal of interleukin-3 (IL-3) from an IL-3-dependent hematopoietic cell line is associated with repartitioning of intracellular calcium and is blocked by enforced $\mathrm{Bcl}-2$ oncoprotein production. Journal of Biological Chemistry, 268: 6511-6519.

57. Pan Z, Bhat MB, Nieminen A-L \& Ma J (2001). Synergistic movements of $\mathrm{Ca}(2+)$ and Bax in cells undergoing apoptosis. Journal of Biological Chemistry, 276: 32257-32263.

58. Dubrez L, Coll JL, Hurbin A, Solary E \& Favrot MC (2001). Caffeine sensitizes human $\mathrm{H} 358$ cell line to p53-mediated apoptosis by inducing mitochondrial translocation and conformational change of BAX protein. Journal of Biological Chemistry, 276: 38980-38987.

59. Csordas G, Madesh M, Antonsson B \& Hajnoczky G (2002). tcBid promotes $\mathrm{Ca}^{2+}$ signal propagation to the mitochondria: control of $\mathrm{Ca}^{2+}$ permeation through the outer mitochondrial membrane. EMBO Journal, 21: 2198-2206.

60. Scorrano L, Ashiya M, Buttle K, Weiler S, Oakes SA, Mannella CA \& Korsmeyer SJ (2002). A distinct pathway remodels mitochondrial cristae and mobilizes cytochrome c during apoptosis. Developmental Cell, 2: 55-67. 